\title{
EFFECTS OF HISTORICALLY PORTRAYED MODELING AND GROUP TREATMENT ON SELF-OBSERVATION: A COMPARISON WITH AGORAPHOBICS*
}

\author{
Paul M. G. Emmelkamp广 and ANK EMmelKamp-BenNer
}

Institute for Clinical and Industrial Psychology. Trans 4. Utrecht. The Netherlands

(Received 2 October 1974)

\begin{abstract}
Summary-The effects of historically portrayed modeling and group treatment on self-observation were determined in a factorial design with agoraphobic patients. Group 1 saw a videofilm and was treated individually; group 2 saw the film and received group treatment; group 3 did not see the film and received individual treatment; and group 4 did not see the film and received group treatment. In the video recording improved 'ex-clients' related their experiences with the same treatment.

Assessments were made at the beginning and at the end of treatment and at the follow-up 1 month later. Assessments were carried out by an independent observer (measurement in rivo. phobic anxiety and avoidance scales. anxious mood and panic). and by the client (phobic anxiety and avoidance scales. FSS. Social Anxiety Scale, SDS and I-E scale).

Group trcatment was just as effective as individual treatment. The videofilm did not increase the effect of the treatment.
\end{abstract}

Recent studies have shown that exposure to the phobic situation in vivo is an effective method of treatment for agoraphobia. If this exposure is prolonged and the client is not allowed to avoid the phobic situation. it is generally called flooding in vivo (Emmelkamp and Wessels, 1975; Hand. Lamontagne and Marks, 1974). The exposure can also be administered step-wise; the client is then allowed to avoid the phobic situation on experiencing undue anxiety as with successive approximation (Agras, Leitenberg and Barlow, 1968; Everaerd, Rijken and Emmelkamp, 1973) and self-observation.

With successive approximation. the clients receive both social reinforcement and feedback from the therapist with regard to the time they spend in the phobic situation. With the self-observation procedure, the clients themselves record the time they spend outside without feeling tense (feedback). but do not receive actual reinforcement from the therapist. In the case of agoraphobics, self-observation was shown to be just as effective as successive approximation (Emmelkamp and Ultee. 1974) and flooding (Emmelkamp. 1974). With selfobservation, the duration of the therapeutic intervention can be decreased because the client learns to act as his own therapist.

The aim of the present study was two-fold: in the first place, to determine whether selfobservation carried out in groups was equally effective as self-observation as an individual treatment. Besides the economic motive of saving time for the therapist, group treatment may have the advantage that some members of the group will serve as coping models for others (Hand et al. . 1974). The second aim was to determine if the effect of self-observation could be increased by the introduction of a video recording in which improved 'ex-clients' related their experiences with the same treatment. This film may be regarded as a form of modeling in which model mastery of problems is portrayed historically rather than enacted currently (Bandura and Barab, 1973).

\section{METHOD}

\section{Design}

Clients were assigned at random, in order of their application, to four different conditions. This rule was broken in two cases in which a client from an individual condition

* A grant from the Netherlands Organization for the Advancement of Pure Research (Z.W.O. no. 58-20) made this study possible. We wish to thank Ton Boekhorst, Paul Goudena and Han Starkenburg for their assistance in the treatment of the clients and Peggy Cohen and Paul Schreurs serving as independent observers.

+ Now at the Academic Hospital. Department of Clinical Psychology, Oostersingel 59. Groningen. The Netherlands. where reprints requests should be sent for the attention of Paul Emmelkamp. 
was moved to a group condition to make the group complete so that it could start. The four experimental conditions were arrived at by means of a factorial design in which the main variables, group treatment and video recording, were varied. Group 1 saw the video film and was treated individually; group 2 saw the film and received group treatment; group 3 did not see the film and received individual treatment; group 4 did not see the film and received group treatment. After a pre-test, four treatment sessions followed for each condition; after these the post-test took place. Then after 1 month without treatment, the follow-up was held.

\section{Treatment}

For experimental reasons. all clients were treated at the Institute. The treatment consisted of self-observation, which technique involves a graduated approach by the subject into the actual feared situation, with instructions to turn back on experiencing undue anxiety. Right from the first session, the client had to enter the phobic situation. Therapist and client agreed upon a route through the city, pretty difficult for the client. leading in a straight line from the Institute. The client had to walk alone without any attribute which might reduce anxiety as umbrella, bicycle, hand-bag, sunglasses. dog. etc. He was given the following instruction: "You must now go into the street and stay outside until you begin to feel uncomfortable or tense. As soon as you no longer feel happy, you must come back straightaway". The client had to record the duration of each trial. After returning at the point of departure for the first time he had to write down the duration in a notebook. He then had to enter the phobic situation in the same way. This procedure was repeated until the 90-min session was over. After each session, the client was given thomework': at home, the client had to carry out the same procedure once for $90 \mathrm{~min}$. At the beginning of each treatment session, the 'home-work' was discussed for 30 min (individually, or in the group). Next. the 90-min self-observation procedure was carried out. and this was then discussed for half-an-hour (individually, or in the group). The first half-hour of the first session was used for getting to know each other (the client and the therapist, or the members of the group); in this session the self-observation procedure lasted only $60 \mathrm{~min}$.

\section{Video recording}

Half the clients saw a video recording, which lasted $23 \mathrm{~min}$. immediately before the treatment was begun. In the film, the following 3 'ex-clients' were interviewed about their experiences with the same treatment:

(1) A woman of $50 \mathrm{yr}$ who had developed agoraphobia shortly after the death of her mother, and had been house-bound for $20 \mathrm{yr}$.

(2) A socially insecure woman of $25 \mathrm{yr}$ who had begun to suffer from agoraphobia 4 yr earlier after a panic attack in a bus.

(3) A middlc-aged man who had begun to be troubled by agoraphobic complaints $5 \mathrm{yr}$ earlier, because of stress produced by his work.

These interviews showed that in the beginning the clients had dreaded the treatment very much. but that it had not been as bad as they had feared.

In the film it was stressed that the clients had improved by practising in the phobic situation, and that after a possible relapse they had to persevere.

The result of the treatment had been positive in all cases, but not to the same extent. There seemed little point in creating unrealistically high expectations.

\section{Individual treatment}

With this condition, each client was treated individually by one therapist. The clients who saw the video recording saw it in the presence of their therapist only. A total of 13 clients were treated individually: 6 did, and 7 did not see the video film.

\section{Group treatment}

With this condition, the 'home-work' and the therapy session were discussed by the whole group: each group was led by two therapists. In the self-observation procedure, 
however, each client took a different route. During this procedure, the clients could meet at the Institute and talk with each other for a short time.

The clients who saw the video recording saw it together with the other members of the group and the therapists. Each group consisted of 4-6 clients. There were 4 groups: 2 did. and 2 did not see the video film.

\section{Therapists}

Therapists were psychologists or advanced psychology students; they were all versed in behaviour therapy. The therapists were supervised by the senior author. At weekly group meetings, the problems connected with the treatment were discussed.

\section{Clients}

Thirty-four clients took part in the investigation, 31 women and 3 men. During the treatment, 3 clients dropped out, 2 because they did not see the point of the treatment, and 1 because she suffered from other and more important problems than agoraphobia. The drop-outs came from the conditions individual treatment, no video recording $(n=2)$, and group treatment, no video recording $(\hat{n}=1)$. A total of 28 women and 3 men completed the treatment. The data of 2 clients could not be used: 1 client refused to co-operate on the post-test, and the data of another client were not used because she was unable to carry out correctly the self-observation procedure due to a physical handicap. The data of the remaining 29 clients, 26 women and 3 men, were processed in the data analysis. The average age of the clients was $34.7 \mathrm{yr}$, ranging from 19 to $54 \mathrm{yr}$. The average duration of the complaint was $6.6 \mathrm{yr}$, ranging from 0.5 to $15 \mathrm{yr}$.

\section{Assessments}

Assessments were carried out at the pre-test, post-test and the follow-up by the client and an independent observer, a clinical psychologist. The assessments were carried out at the home of the client.

Measurement in vivo. The client was instructed to go into the street and to stay outside until he began to feel uncomfortable or tense; then he had to come back straightaway. The duration of time spent outside was measured by the independent observer.

Phobic anxiety and avoidance scales. Client and independent observer rated 5-phobic situations on 9-point scales for phobic anxiety and phobic avoidance respectively (Watson and Marks, 1971). The scores for the main phobia (street) were calculated separately; the scores for the other four phobias were added up.

Anxious mood and panic. The independent observer rated the client on 9-point scales for anxious mood and panic (Watson and Marks, 1971).

Moreover the client filled in the following questionnaires: Fear Survey Schedule (FSS) (Wolpe and Lang, 1964; range 76-380); Social Anxiety Scale (SAS) (Willems. Tuender-de Haan and Defares, 1973; range 0-96); Internal-External Control Scale (I-E) (Rotter, 1966; range 12-71); and Self-rating Depression Scale (SDS) (Zung, 1965; range 23-92). Variations adapted for use in the Netherlands were used.

Expectancy scale. Immediately before starting the self-observation procedure for the first time, clients rated how much they expected to gain from therapy on three separate scales (Stern and Marks, 1973).

\section{RESULTS}

At the beginning of the treatment, significant differences between the various conditions were found on the FSS $(F=3.19, p<0.05)$, SAS $(F=5.54, p<0.01)$ and on anxious $\operatorname{mood}(F=3.26, p<0.05)$. For this reason analyses of covariance were applied to the data, using the pre-test as covariate.

The treatment effect was tested with two-tailed $t$-tests for dependent samples. From the post-test, it appeared that the treatment resulted in a significant improvement on a large number of variables (see Table 1). Analyses of covariance on the results of the post-test showed that the individual treatment was superior to the group treatment $(F=6.05$, 
Table 1. Treatment effect at the post-test.

\begin{tabular}{|c|c|c|c|c|c|c|c|}
\hline & & \multicolumn{2}{|c|}{ Pre-test } & \multicolumn{2}{|c|}{ Post-test } & \multirow[b]{2}{*}{$\underline{\mathrm{d}} \underline{\underline{F}}$} & \multirow[b]{2}{*}{$\underline{t}$} \\
\hline & & M & SD & M & SD & & \\
\hline \multicolumn{2}{|c|}{ In vivo measurement } & 8.3 & 5.5 & 30.6 & 26.4 & 28 & $-4.46 \$$ \\
\hline Phobic anxiety & $\mathrm{S}^{\mathrm{c}}$ & 6.1 & 2.0 & 3.6 & 2.7 & 28 & $3.90 \$$ \\
\hline street & 10 & 6.1 & 1.9 & 3.4 & 2.2 & 28 & $4.94 \$$ \\
\hline \multirow{2}{*}{ other phobias } & fc & 22.4 & 6.7 & 15.7 & 7.4 & 28 & $3.59 \neq$ \\
\hline & lo & 23.5 & 6.0 & 17.4 & 6.9 & 28 & $3.60 \neq$ \\
\hline Phobic avoidance & c & 6.7 & 1.6 & 4.1 & 2.8 & 28 & $4.36 \$$ \\
\hline street & 10 & 6.9 & 1.5 & 4.3 & 2.5 & 28 & $4.81 \S$ \\
\hline \multirow{2}{*}{ other phobias } & $f^{c}$ & 24.2 & 6.3 & 18.0 & 7.6 & 28 & $3.39 \neq$ \\
\hline & lo & 25.7 & 6.3 & 20.4 & 6.7 & 28 & $3.13 \neq$ \\
\hline Panic & & 0.5 & 1.4 & 1.3 & 2.4 & 28 & -1.47 \\
\hline Anxious Mood & & 3.0 & 2.1 & 3.8 & 2.3 & 28 & $2.06 *$ \\
\hline FSS & & 193.9 & 43.0 & 174.8 & 46.6 & 27 & 1.59 \\
\hline SAS & & 55.4 & 15.0 & 49.8 & 15.3 & 27 & 1.41 \\
\hline I-E scale & & 41.8 & 9.6 & 39.1 & 9.0 & 28 & 1.10 \\
\hline $\mathrm{SDS}$ & & 55.2 & 10.6 & 49.0 & 31.4 & 28 & $2.16 *$ \\
\hline
\end{tabular}

$\begin{array}{lll}* & \mathrm{p}<0.0 \mathrm{u} & \mathrm{C}=\text { Client } \\ \dagger & \mathrm{p}<0.02 & 0=\text { Independent Observer } \\ \dagger & \mathrm{p}<0.01 & \\ \S & \mathrm{p}<0.001 & \end{array}$

$p<0.05$ ) on the FSS only. It also appeared that on the I-E scale the condition without video recording had been superior to the condition with video recording $(F=5.01$, $p<0.05$ ).

Between post-test and follow-up, no treatment was given. The scores at the follow-up did not differ significantly from those at the post-test. Analyses of covariance yielded no significant differences between the different conditions.

Correlation coefficients were computed between the expectancy-rating of the client at the start of the treatment and three outcome measures: measurement in vivo, phobic anxiety scale—street (client's and observer's ratings combined), and phobic avoidance scale-street (client's and observer's ratings combined). For the post-test these correlation coefficients were one-tailed tested: measurement in vivo 0.24 , phobic anxiety 0.35 $(p<0.05)$, and phobic avoidance $0.43(p<0.01)$.

\section{DISCUSSION}

From the results on the phobic anxiety and avoidance scales-street and on the measurement in vivo. it can be seen that the treatment was effective in spite of the small number of sessions (four). The decrease in anxiety and avoidance was generalized to other phobias, as measured by the phobic anxiety and avoidance scales - other phobias. However, this effect of generalization was not significant on the FSS and SAS. It is noteworthy that at the end of the treatment clients reported significantly less depressive feelings than at the beginning of the treatment-as measured by the SDS - an effect which was retained at the follow-up.

Group treatment was just as effective as individual treatment. The individual treatment was superior to the group treatment on only one variable (FSS), but this difference had disappeared at the follow-up. So we may conclude that agoraphobics can be treated in groups, which means a considerable time-saving for the therapists.

Although in a few groups some members might have acted as coping models, this was not the case in all the groups. For instance, one group was dominated by a client who repeatedly simulated heart attacks, and this had a distinctly negative influence on the other members of the group. For this reason, two clients left after the first session; one of them was persuaded to return after all. Experiences such as these seem to make it desirable to 
find suitable criteria for matching clients in different groups instead of assigning them to the groups at random.

In the present study the video recording did not have an effect on the treatment. Only on one of the 30 variables (the I-E) was a significant video effect found. But this effect was opposed to the hypothesis, and may have been due to chance. The fact that historically portrayed modeling did not have any effect in this study may be due to the following factors: In the first place, it is possible that historically portrayed modeling would have an effect if the models were presented in real life instead of in a film, as is done for instance in such self-help groups as Alcoholics Anonymous. Another possibility is that historically portrayed modeling would be more effective if it were repeated during the treatment. In this study, the clients saw the video film only once, before the treatment was begun. The information from the film might have been forgotten in the course of the treatment. Finally, the explanation of the treatment to the clients in all conditions may have induced high expectations from the treatment, to which the video recording could no longer contribute anything. After the explanation of the treatment. there was no difference between the expectations of the clients who had seen the film and those who had not: in both conditions the clients expected on the average that it was "likely" that they would be helped by the treatment, and that they would be "much better" "within a few months". That expectancy of therapeutic gain can influence the effect of the treatment is indicated by the significant correlations between the expectancy scale and the improvement made.

It was notable that clients dropped out only in the condition without video film. The number of drop-outs, however, is too small $(n=3)$ to warrant drawing any conclusions from this fact.

\section{REFERENCES}

Agras W. S.. LeItenberg H. and Barlow D. H. (1968) Social reinforcement in the modification of agoraphobia. Archs gen. Psychiat. 19, 423-427.

Bandura A. and Barab P. G. (1973) Processes governing disinhibitory effects through symbolic modeling. $J$. abnorm. Psychol. 82, 1-9.

EmmelKamp P. M. G. (1974) Self-observation versus flooding in the treatment of agoraphobia. Behat. Res. \& Therapy 12, 229-237.

EmmelkamP P. M. G. and Ultee C. A. (1974) A comparison of "successive approximation" and "self-observation" in the treatment of agoraphobia. Behav. Therapy 5, 605-613.

EMmelkamp P. M. G. and Wessels H. (1975) Flooding in imagination vs flooding in vivo: a comparison with agoraphobics. Behat. Res. \& Therapy 13, 7-15.

Everaerd W. T. A. M., Rijken H. M. and Emmelkamp P. M. G. (1973) A comparison of flooding and successive approximation in the treatment of agoraphobia. Behav. Res. \& Therapy 11, 105117.

HAND I.. LAmontagne Y. and MARKs I. M. (1974) Group exposure (flooding) in vivo for agoraphobics. Br. $\mathrm{J}$. Psychiat. 124, 588-602.

RotTer J. B. (1966) Generalized expectancies for internal vs external control of reinforcement. Psychol. Monogr. $80,1-28$.

STER N R. and MARKS I. (1973) Brief and prolonged flooding: a comparison in agoraphobic patients. Archs gen. Psychiat. 28, 270-276.

WATSON J. P. and MARKS I. M. (1971) Relevant and irrelevant fear in flooding: a cross-over study of phobic patients. Behat. Therapy 2, 275-295.

Willems L. F. M., Tlender-De HaAn H. A. and Defares P. B. (1973) Een schaal om sociale angst te meten. Ned. Tijdschr. v.d. Psvchol. 28, $415 \cdot 422$.

WOLPE J. and LANG P. J. (1964) A fear survey schedule for use in behavior therapy. Behat. Res. \& Therapy 2 , $27-30$.

Zung W. W. K.(1965) A self rating depression scale. Archs gen. Psychiat. 12. 63-70. 